A 43-year-old male was referred by a veterinarian who evaluated his dog for a seizure and suspected a toxic lead exposure for both. He refurbished houses, removing old paint, and complained of decreased cognition, fatigue, and muscle cramps. He had a depressed affect, postural tremor, right arm weakness with partial denervation on EMG, and borderline-low sensory nerve action potential (SNAP) amplitudes. A mild anemia and elevated serum and urine lead levels supported a diagnosis of lead neuropathy. Chelation therapy increased urine lead excretion without symptomatic improvement. His brother worked part-time with him and developed similar findings, but also had difficulty chewing, dysphagia, perioral twitching, gynecomastia, and multifocal denervation of extremity and facial muscles. His lead levels were not elevated, but an androgen receptor mutation identified on the $X$ chromosome for both brothers confirmed the diagnosis of $X$-linked bulbospinomuscular atrophy (Kennedy's disease). (c) 1994 John Wiley \& Sons, Inc.

Key words: Kennedy's disease - motor neuron disease - lead neuropathy - bulbospinomuscular atrophy

MUSCLE \& NERVE 17:419-423 1994

\title{
X-LINKED BULBOSPINOMUSCULAR ATROPHY (KENNEDY'S DISEASE) MASQUERADING AS LEAD NEUROPATHY
}

\author{
JAMES W. ALBERS, MD, PhD, and MARK B. BROMBERG, MD, PhD
}

Development of an unusual neurologic disorder in the presence of a documented toxic exposure usually results in the diagnosis of a toxic-induced syndrome. We present a patient diagnosed with lead-induced neuropathy, despite several features atypical of lead intoxication. Because of the rarity of this disorder, the atypical features were minimized and attributed to the limited clinical experience using current electrodiagnostic methods. Although neurologic symptoms and signs progressed despite chelation therapy, identification of a younger sibling with potential lead exposure tentatively supported the diagnosis of lead neuropathy for both. However, the additional findings in

From the Department of Neurology, University of Michigan Medical Center, Ann Arbor, Michigan.

Presented in part at the annual meeting of the American Academy of Neurology, New York, NY. April 1993.

Acknowledgments: The help of those who participated in the evaluation and care of these patients is gratefully acknowledged, particularly James F. Selwa, MD, Michael Heublum, MD, and John Visser, MD.

Address reprint requests to James W. Albers, MD, PhD, Department of Neurology, 1914 Taubman Center, University of Michigan Medical Center, Ann Arbor, Ml 48109-0316.

Accepted for publication October 16, 1993

CCC 0148-639x/94/040419-05

(c) 1994 John Wiley \& Sons, Inc the younger sibling of a normal lead level, perioral twitching, postural tremor, and gynecomastia suggested the diagnosis of X-linked bulbospinomuscular atrophy (Kennedy's disease), ${ }^{8}$ and the recently identified genetic marker for Kennedy's disease $^{10}$ confirmed a mutation of the androgen receptor gene and the correct diagnosis in both brothers.

\section{CASE REPORTS}

Case 1. A 43-year-old male prepared external surfaces of old houses with multiple layers of paint, presumably leaded. He typically used a power sander with limited respiratory protection (charcoal filter respirator abandoned for a paper mask). At age 38, he experienced decreased cognition, easy fatigability, muscle cramps, and arm weakness, but came to medical attention 2 years later when his dog had a seizure, attributed by a veterinarian to lead exposure. The patient's physician found an elevated serum lead level and referred him to an occupational medicine specialist for chelation therapy. Social and family histories were thought to be unremarkable. Examination revealed mild obesity. There was no gingival lead line. He appeared depressed and had mild difficulty with short-term memory and calculations. There was a fine postural tremor and mild weak- 
ness (MRC grade 4 to 5-) of the right triceps, biceps brachii, deltoid, wrist and finger extensors, and thenar muscles. The right biceps and brachioradialis reflexes were diminished. Sensation was normal. Lead levels were elevated in the serum $(0.71 \mu \mathrm{g} / \mathrm{mL}$; normal $<0.3)$ and urine $(90 \mu \mathrm{g} / \mathrm{L}$; normal $<80$ ), and he had a mild anemia (hemoglobin of $13.0 \mathrm{~g} / \mathrm{dL}$ ) and a borderline-elevated urinary delta-aminolevulinic acid $(6.4 \mathrm{mg} / \mathrm{TV}$; normal $<5.0$ ). Nerve conduction studies (Table 1) demonstrated borderline-low amplitude sensory nerve action potentials (SNAPs) and prolonged median distal latencies. EMG (Table 2) demonstrated partial denervation in muscles of $\mathrm{C}-5-7$ innervation, sparing paraspinal muscles.

Chelation challenge with calcium-edetic acid (Ca-EDTA; $1 \mathrm{~g}$ in $250 \mathrm{~mL}$ of $5 \%$ dextrose solution) produced a greater than tenfold elevation in lead excretion $(1058 \mu \mathrm{g} / \mathrm{L})$, suggesting an increased body burden. Because of suspected lead neuropathy, he avoided additional exposure and his physician continued chelation therapy for several months. However, he reported progressive weakness and mild distal sensory loss. A serum lead level 2 years later was $0.21 \mu \mathrm{g} / \mathrm{mL}$.

Case 2. The 38-year-old brother of case 1 who worked part-time with his brother was referred for evaluation of possible motor neuron disease. At age 32 , he noted a hand tremor, followed by weakness of his arms and right leg, decreased sensation in his legs, and neck pain attributed to a herniated cervical disk for which he underwent a cervical laminectomy. His pain resolved but he developed exercise-induced muscle cramping, muscle twitching, rapid fatigability, and difficulty chewing and swallowing, suggestive of motor neuron disease. At an earlier age gynecomastia was noted, but gonadal function and karyotype were normal.

Examination at age 38 demonstrated asymmetric gynecomastia (Fig. 1). Testicles were of normal size. Mental status was normal. There were vermicular facial and tongue movements, a postural tremor, and mild weakness (MRC scale; R/L) of wrist extensor $(4+/ 5)$, finger extensor $(5-/ 5-)$, finger abductor $(4+/ 4+)$, and gluteus maximus $(4+/ 3)$ muscles. Reflexes $(\mathrm{R} / \mathrm{L})$ were asymmetric in the arms $(1+/ 2+)$ and increased at the knees $(3+1$ $3+)$. No pathologic reflexes were demonstrated. Sensation was normal. The serum creatine kinase (CK) was $358 \mathrm{IU} / \mathrm{L}$ (normal $<240$ ), and the CSF protein was $82 \mathrm{mg} / \mathrm{dL}$ (normal <45). Serum and 24-h urine lead levels were not elevated. SNAP amplitudes were borderline-low (Table 3), and EMG (Table 4) demonstrated multifocal denervation and reinnervation in the three extremities tested, and in thoracic paraspinal and facial muscles. These electrodiagnostic features combined with the constellation of bulbar complaints, gynecomastia, and postural tremor suggested the diagnosis of Kennedy's disease.

Additional Evaluation. Serum samples were sent to the Molecular Diagnostic Laboratory at the University of Pennsylvania. Polymerase chain reaction (PCR) amplification of DNA segments on the $\mathrm{X}$ chromosome revealed an increased size of the CAG repeats on the antigen receptor gene for both patients, characteristic of Kennedy's disease.

\section{DISCUSSION}

$\mathrm{X}$-linked bulbospinomuscular atrophy ${ }^{8}$ is characterized by slowly progressive degeneration of bulbar and spinal motor neurons combined with en-

\begin{tabular}{|c|c|c|c|c|c|c|}
\hline \multirow[b]{2}{*}{ Nerve } & \multicolumn{2}{|c|}{ Amplitude $(\mu \vee$ or $\mathrm{mV})$} & \multicolumn{2}{|c|}{ Conduction velocity $(\mathrm{m} / \mathrm{s})$} & \multicolumn{2}{|c|}{ Latency (ms) } \\
\hline & $R / L$ & Normal & $R / L$ & Normal & $R / L$ & Norma \\
\hline \multicolumn{7}{|l|}{ Sensory } \\
\hline Median & $4 / 4$ & $>15$ & $55.9 /$ & $>53$ & $4.3 / 4.6$ & $<3.7$ \\
\hline Uinar & $2 / 1.5$ & $>10$ & & & $3.7 / 3.4$ & $<3.5$ \\
\hline Radial & $5 /$ & $>10$ & & & $2.5 /$ & $<2.7$ \\
\hline Sura! & 5.8 & $>6$ & & & 4.11 & $<4.2$ \\
\hline \multicolumn{7}{|l|}{ Motor } \\
\hline Median & $3.9 / 3.5$ & $>4$ & $56.8 / 55.5$ & $>49$ & $4.9 / 5.5$ & $<4.4$ \\
\hline Median F wave & & & & & $29.4 / 30.6$ & $<31$ \\
\hline Uinar & $10.9 /$ & $>6$ & $59.0 /$ & $>49$ & $2.8 /$ & $<3.5$ \\
\hline Ulnar F wave & & & & & $28.9 /$ & $<31$ \\
\hline Radial & $6.4 / 7.6$ & $>3$ & & & $3.7 / 3.5$ & $<3.5$ \\
\hline
\end{tabular}




\begin{tabular}{|c|c|c|c|c|c|c|}
\hline \multirow[b]{3}{*}{ Muscle } & \multicolumn{2}{|c|}{ Spontaneous activity } & \multicolumn{4}{|c|}{ Voluntary activity } \\
\hline & \multirow{2}{*}{$\begin{array}{l}\text { Fibrillation } \\
\text { potentials }\end{array}$} & \multirow{2}{*}{$\begin{array}{c}\text { Fasciculation } \\
\text { potentials }\end{array}$} & \multicolumn{4}{|c|}{ Motor unit action potentials } \\
\hline & & & Recrt. & Ampl. & Dur. & $\%$ poly \\
\hline R Biceps brachii & $2+$ & 0 & $\downarrow 2+$ & $\uparrow 2+$ & $\uparrow 2+$ & $\uparrow 2+$ \\
\hline R Triceps & 0 & 0 & $\downarrow 1+$ & $\uparrow 1+$ & $\uparrow 1+$ & $\uparrow 1+$ \\
\hline R Deltoid & $2+$ & $1+$ & $\downarrow 2+$ & $\uparrow 2+$ & $\uparrow 2+$ & $\uparrow 2+$ \\
\hline R Ext digitorum communis & 0 & 0 & $\downarrow 1+$ & $\uparrow 1+$ & $\uparrow 1+$ & $\uparrow 1+$ \\
\hline R FDI (hand) & 0 & 0 & $N$ & $N$ & $N$ & $N$ \\
\hline R Abd. pollicus brevis & 0 & 0 & $N$ & $N$ & $N$ & $N$ \\
\hline R Cervical paraspinal & 0 & 0 & $N$ & $N$ & $N$ & $N$ \\
\hline L Biceps brachii & 0 & 0 & $N$ & $N$ & $N$ & $N$ \\
\hline L FDI (hand) & 0 & 0 & $N$ & $N$ & $N$ & $N$ \\
\hline$R$ Anterior tibialis & 0 & 0 & $N$ & $N$ & $N$ & $N$ \\
\hline R FDI (pedis) & 0 & 0 & $N$ & $N$ & $N$ & $N$ \\
\hline
\end{tabular}

docrine system abnormalities. Neuromuscular findings include lingual and facial twitching (contraction-like fasciculations or grouped discharges), muscle weakness and cramps, postural tremor, reduced reflexes, and elevated serum CK levels. ${ }^{1,8,12,18,19}$ Electrodiagnostic abnormalities include low SNAP amplitudes and EMG evidence of widespread denervation and reinnervation. ${ }^{6,12}$ Signs of androgen insensitivity include gynecomastia, impotence, testicular atrophy, oligospermia and azoospermia, and elevated serum gonadotropin levels. ${ }^{18} \mathrm{An}$ androgen receptor mutation on the $\mathrm{X}$ chromosome is distinguished by an increased size of a polymorphic tandem CAG repeats within the first exon of the gene, with conflicting evidence for a correlation between the degree of genetic abnormality (number of tandem CAG repeats) and the clinical expression. ${ }^{1,7,10}$ The younger brother had characteristic features of Kennedy's disease. The older brother had no abnormal facial movements, bulbar symptoms or signs, or gynecomastia.

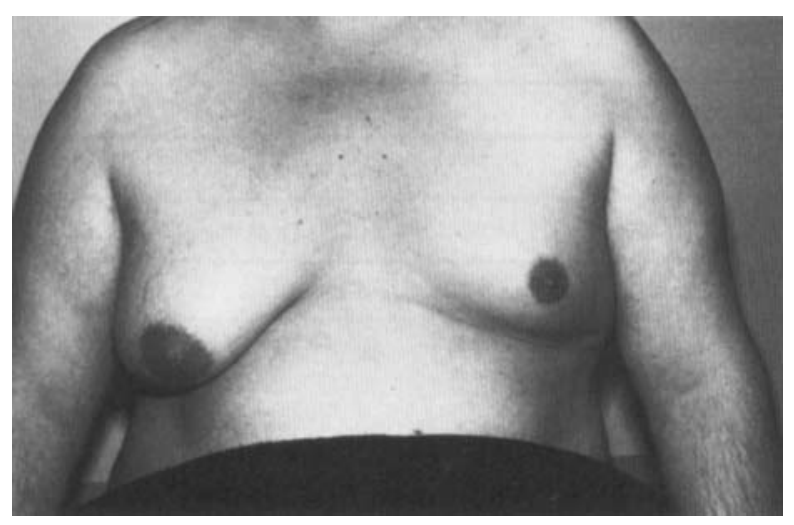

FIGURE 1. Photograph of the younger brother (case 2) demonstrating asymmetric gynecomastia.
Nevertheless, phenotypic expression between and within families is variable. ${ }^{\mathrm{P}}$ Both brothers had asymmetric weakness with chronic denervation and reinnervation consistent with adult-onset motor neuron disease, although both had nerve conduction evidence of a sensory neuropathy.

The role of lead exposure in these patients is unclear. The systemic effects of lead intoxication are widespread, involving hemopoietic, endocrine, hepatic, reproductive, and nervous systems. The clinical suspicion of lead toxicity was based upon a plausible exposure history and limited evidence of occupational protection, and the older brother had intermittent abdominal pain and constipation, anemia, and neuropathy, all consistent with lead toxicity. ${ }^{20}$ His lead levels were elevated, and provocative chelation produced abnormal 24-h urinary lead excretion exceeding $1 \mathrm{mg} .{ }^{13}$ The younger brother did not have similar laboratory abnormalities, but his exposure was minimal compared to his brother.

Lead neuropathy reportedly involves the upper before the lower extremities, ${ }^{14}$ but neither brother had the classic pattern of wrist drop resembling radial nerve palsy. Although the peripheral manifestations of lead toxicity are exceedingly rare, descriptions exist of asymmetric proximal arm or intrinsic hand muscle involvement resembling a progressive muscular atrophy. ${ }^{11,15}$ It is unclear whether the abnormal SNAPs should have excluded the diagnosis of lead neuropathy, because few reports exist using modern electrodiagnostic techniques. The patient presented by $\mathrm{Oh}^{11}$ had absent SNAPs at various times, but also reported heavy illicit alcohol use. An art conservator who restored an antique tapestry using a leaded-pigment recovered with the tapestry from the same 


\begin{tabular}{|c|c|c|c|c|c|c|}
\hline \multirow[b]{2}{*}{ Nerve } & \multicolumn{2}{|c|}{ Amplitude $(\mu \mathrm{V}$ or $\mathrm{mV})$} & \multicolumn{2}{|c|}{ Conduction velocity $(\mathrm{m} / \mathrm{s})$} & \multicolumn{2}{|c|}{ Latency (ms) } \\
\hline & $\mathrm{R}$ & Normal & $R$ & Normal & R & Norma \\
\hline \multicolumn{7}{|l|}{ Sensory } \\
\hline Median & 12 & $>15$ & 56.0 & $>53$ & 3.3 & $<3.7$ \\
\hline Uinar & 7 & $>10$ & & & 3.3 & $<3.5$ \\
\hline Radial & 12 & $>10$ & & & 2.2 & $<2.7$ \\
\hline Sural & 7 & $>6$ & & & 3.8 & $<4.2$ \\
\hline \multicolumn{7}{|l|}{ Motor } \\
\hline Median & 6.0 & $>4$ & 62.6 & $>49$ & 4.2 & $<4.4$ \\
\hline Median F wave & & & & & & \\
\hline Ulnar & 6.6 & $>6$ & 60.8 & $>49$ & 2.8 & $<3.5$ \\
\hline Ulnar $F$ wave & & & & & 29.8 & $<31$ \\
\hline Peroneal & 5.8 & $>2$ & 45.0 & $>41$ & 4.9 & $<6.1$ \\
\hline Peroneal $F$ wave & & & & & 49.8 & $<55$ \\
\hline
\end{tabular}

tomb developed lead poisoning with sensory and motor conduction abnormalities consistent with a diffuse polyneuropathy. ${ }^{5}$ Lead-exposed automotive workers had similar conduction abnormalities, ${ }^{16}$ but no abnormalities were found in a crosssectional evaluation of lead-exposed workers at a storage battery manufacturing plant. ${ }^{17}$

A relationship between occult plumbism and motor neuron disease has been questioned. ${ }^{3}$ Isolated case reports relate chronic occupational lead exposure to combined anterior horn cell and pyramidal tract degeneration indistinguishable from ALS, with partial recovery after chelation therapy. ${ }^{15}$ Kerlander and Patton ${ }^{9}$ found elevated anterior horn cell lead levels in ALS patients compared to controls, and epidemiologic evaluations implicated antecedent lead exposure as a potential risk factor for ALS, although lead exposure could have been responsible for ALS in only a minority of the patients. ${ }^{2}$ The differential diagnosis of motor neuron disease commonly includes lead toxicity, but a pathophysiologic connection is unsub- stantiated, and trials of chelation therapy in patients with motor neuron disease have been ineffective. ${ }^{4}$

Although the diagnosis of lead neuropathy seemed secure in the older brother, it was based upon the temporal association of lead exposure and nonspecific neurologic symptoms and signs. The elevated body burden of lead confirmed exposure without establishing toxicity, and the role of provocative chelation in establishing an abnormal body burden remains controversial, particularly in the presence of known occupational exposure. Recognition of the cardinal features of gynecomastia, tremor, and abnormal facial movements in the younger brother, combined with borderline-low sensory responses in both patients, raised the suspicion of Kennedy's disease, and identification of the genetic marker established the diagnosis. The absence of facial or bulbar findings in the older brother likely represents phenotypic variability, and while asymmetric weakness is uncharacteristic of previous reports, asymmetry at

\begin{tabular}{|c|c|c|c|c|c|c|}
\hline \multirow[b]{3}{*}{ Muscle } & \multicolumn{2}{|c|}{ Spontaneous activity } & \multicolumn{4}{|c|}{ Voluntary activity } \\
\hline & \multirow{2}{*}{$\begin{array}{l}\text { Fibrillation } \\
\text { potentials }\end{array}$} & \multirow{2}{*}{$\begin{array}{l}\text { Fasciculation } \\
\text { potentials }\end{array}$} & \multicolumn{4}{|c|}{ Motor unit action potentials } \\
\hline & & & Recrt. & Ampl. & Dur. & $\%$ poly \\
\hline R Biceps brachii & $2+$ & 0 & $\downarrow 2+$ & $\uparrow 2+$ & $\uparrow 2+$ & $\uparrow 2+$ \\
\hline R FDI (hand) & $1+$ & 0 & $\downarrow 1+$ & $\uparrow 2+$ & $\uparrow 2+$ & $\uparrow 2+$ \\
\hline $\mathrm{R}$ Thoracic paraspinal & $1+$ & 0 & & & & \\
\hline L Vastus medialis & 0 & 0 & $\downarrow 2+$ & $\uparrow 2+$ & $\uparrow 1+$ & $\uparrow 1+$ \\
\hline L Anterior tibialis & $1+$ & $1+$ & $\downarrow 1+$ & $\uparrow 2+$ & $\uparrow 1+$ & $\uparrow 1+$ \\
\hline L Medial gastrocnemius & $2+$ & 0 & $\downarrow 2+$ & $\uparrow 2+$ & $\uparrow 1+$ & $\uparrow 1+$ \\
\hline L Orbicularis oris & $2+$ & 0 & $\downarrow 1+$ & $\uparrow 2+$ & $\uparrow 1+$ & $\uparrow++$ \\
\hline L Tongue & 0 & 0 & $N$ & $N$ & $N$ & $N$ \\
\hline
\end{tabular}


some stage is typical of most forms of motor neuron disease.

\section{REFERENCES}

1. Amato AA, Prior TW, Barohn RJ: Kennedy's disease: a clinicopathologic correlation with mutations in the androgen receptor gene. Neurology 1993;43:791-794.

2. Armon C, Kurland LT, Daube JR, O'Brien PC: Epidemiologic correlates of sporadic amyotrophic lateral sclerosis. Neurology 1991;41:1077-1084.

3. Campbell AMG, Williams ER, Barltrop D: Motor neurone disease and exposure to lead. $J$ Neurol Neurosurg Psychiatry 1970;33:877-885.

4. Conradi S, Ronnevi LO, Norris FH: Motor neuron disease and toxic metals. Adv Neurol 1982;36:201-231.

5. Fischbein A, Wallace J, Anderson KE, Sassa S, Kon S, Rohl AN, Kappas A: Lead poisoning in an art conservator. JAMA 1982;247:2007-2009.

6. Harding AE, Thomas PK, Baraitser M, Bradbury PG, Morgan-Hughes JA, Ponsford JR: X-linked recessive bulbospinal neuronopathy: a report of ten cases. J Neurol Neurosurg Psychiatry 1982;45:1012-1019.

7. Igarashi S, Tanno Y, Onodera O: Strong correlation between the number of CAG repeats in androgen receptor genes and the clinical onset of features of spinal and bulbar muscular atrophy. Neurology 1992;42:2300-2302.

8. Kennedy WR, Alter M, Sung JH: Progressive proximal spinal and bulbar muscular atrophy of late onset. A sex-linked recessive trait. Neurology 1968;18:671-680.

9. Kurlander HM, Patten BM: Metals in spinal cord tissue of patients dying of motor neuron disease. Ann Neurol 1979, 6:21-24
10. La Spada AR, Wilson EM, Lubahn DB, Harding AE, Fischbeck KH: Androgen receptor gene mutations in X-linked spinal and bulbar muscular atrophy. Nature 1991; $352: 77-79$

11. Oh SJ: Lead neuropathy: case report. Arch Phys Med Rehabil 1975;56:312-317.

12. Olney RK, Aminoff MJ, So YT: Clinical and electrodiagnostic features of X-linked recessive bulbospinal neuronopathy. Neurology 1991;41:823-828.

13. Rieders F: Current concepts in the therapy of lead poisoning, in Seven MJ (ed): Metal Binding in Medicine. Philadelphia, Lippincott, 1960, pp 143-145.

14. Seto DSY, Freeman JM: Lead neuropathy in childhood. $A m$ J Dis Child 1964;107:337.

15. Simpson JA, Seaton DA, Adams JF: Response to treatment with chelating agents of anaemia, chronic encephalopathy, and myelopathy due to lead poisoning. $J$ Neurol Neurosurg Psychiatry 1964;27:536-541.

16. Singer R, Valciukas JA, Lilis R: Lead exposure and nerve conduction velocity: the differential time course of sensory and motor nerve effects. Neurotoxicology 1983;4:193-202.

17. Triebig $G$, Weltel $D$, Valentin $H$ : Investigations on neurotoxicity of chemical substances at the workplace. V. Determination of the motor and sensory nerve conduction velocity in persons occupationally exposed to lead. Int Arch Occup Environ Health 1984;53:189-203.

18. Warner CL, Servidei S, Lange DJ: X-linked spinal muscular atrophy (Kennedy's syndrome). Arch Neurol 1990;47: $1117-1120$.

19. Wilde J, Moss T, Thrush D: X-linked bulbo-spinal neuronopathy: a family study of three patients. J Neurol Neurosurg Psychiatry 1987;50:279-284.

20. Windebank AJ: Metal neuropathy, in Dyck PJ, Thomas PK, Griffin JW, Low PA, Poduslo JF (eds): Peripheral Neuropathy. Philadelphia, Saunders, 1993, pp 1549-1570. 